\title{
LA XVI ASAMBLEA DE LA SOCIEDAD ESPAÑOLA DE OFTALMOLOGÍA HISPANO AMERICANA (1930)
}

\author{
LÓPEZ DE LETONA C ${ }^{1}$
}

Los días 15 al 17 de setiembre de 1930 tuvo lugar en Santiago de Compostela la XVI Asamblea de la S O H A que estaba presidida durante aquellos años por D. Tomás Blanco Bandebrande, catedrático de nuestra disciplina en Valencia. El secretario era D. Francisco Poyales del Fresno, quien había sido como tantos otros, discípulo de Manuel Márquez y teniendo ocasión de viajar al extranjero conociendo al famoso Dr. Smith, médico inglés que diseñó un procedimiento para la intervención de catarata.

Comenzó la reunión con una sesión inaugural en la que tomó primero la palabra el presidente y despues el secretario.

El primero de ellos habló a la importancia de este tipo de celebraciones científicas, agradeciendo las facilidades que les habían dado las autoridades gallegas para este evento.

La memoria de secretaría, resumió la reunión anterior, que había tenido lugar en Zaragoza; allí el oculista Lacarrere se había referido a la bio microscopía de la córnea con la lámpara de doble hendidura.

También habían intervenido los más destacados profesionales del momento, entre ellos Castroviejo, Menacho, Márquez,... etc.

Brevemente habló también de los que habían fallecido: Rafael Repiso, Teobaldo Busto y Manuel Villar.

Las sesiones científicas fueron cuatro y cada una estuvo presidida por un destacado oftalmólogo.

En la primera de ellas se ofreció lo que se denomino «Tema oficial» que vendría a ser las actuales ponencias oficiales. Fue el profesor Soria, catedrático de la especialidad en Barcelona quien la expuso y el asunto fue «Bio microsocopía del iris».

Recogía las técnicas exploratorias existentes basadas sobre todo en la utilización del microscopio de Czapski y la lámpara de hendidura de Gulstrad.

Exponía enseguida los resultados, comenzando por la exploración del iris normal así como las anomalías congénitas del mismo, así la heterocromía afección al parecer algo más frecuente de lo que podría pensarse. Igualmente otras entidades patológicas como la membrana pupilar persistente refieriéndose tambien en particular a los procesos traumáticos, los inflamatoria y el glaucoma.

En esta sesión tambien presentaron comunicaciones otros oftalmólogos, entre ellos el mismo Tomas Blanco: «Complicaciones queráticas del catarro primaveral de Soemisch» y sobre todo el prestigioso catalán Hermenegildo Arruga: «La extracción intracapsular de la catarata». Ofrecía ilustraciones sobre material vario, técnicas, ... etc.

La segunda sesión fue presidida precisamente por Arruga quien tambien disertó sobre el escotoma centellenate, igualmente Fernández Balbuena que ofreció una curiosa comunicación titulada así: «La infección consecutiva a la herida de la córnea por las puas del erizo del castaño, es frecuentemente una micosis».

Por su parte en la tercera sesión, que fue presidida por el catedrático de Zaragoza Palomar de la Torre se ofrecieron un total de cinco nuevas cominicaciones, todos los autores nos son más o menos conocidos, así el Dr. López Enriquez, que fue había trabajado al lado del preclaro histólogo Río Hortega se refirió a un caso de desgarros parciales o incompletos de la retina en los desprendimientos de esta membrana.

No podía faltar Galo Leoz Ortín que disertó sobre la hipertensión arterial y el fondo del ojo, también un oftalmólogo catalán: Gómez Márquez (Que no tenía nada que ver con Manuel Márquez), habló sobre determinadas consideraciones acerca de los diversos tiempos de la dacriocisto rinostomía.

Finalmente en esta sesión participó tambien Castroviejo, de Logroño, de la familia de los Castroviejo. Fue «Nevocarcimoma epibulbar con invasion externa de la córnea». Precisamente el análisis histopatológico de la afección se había efectuado por Ramon Castroviejo Briones que andaba por aquellos años trabajando en la Fisher Clinic de Chiago.

\footnotetext{
1 Doctor en Medicina. IOBA. Valladolid. España.

E-mail: berta@ioba.med.uva.es
} 
La cuarta y última fue presidida por un Dr. Salcedo, del que a decir verdad lo ignoramos casi todo. Debía ser una sesión destinada a miscelánea en la que intervino una vez más Manuel Márquez «A cerca de la visión estereoscópica anaglifa». Igualmente Mérida Nicolich, y los oftalmólogos gallegos: Sánchez Molquera (Iridociclits palúdica) y Sal Lence (Vitaminoterapia en Oftalmología).

Como colofón a todo hubo otros trabajos que no se discutieron «Por no hallarse presentes sus autores o por falta de tiempo», entre ellos uno de M. Mena- cho: «Las exigencias de la industria respecto a la mano de obra en relación con la aptitud visual», otro de López Enriquez: «Práctica sencilla para reforzar la accióon de los colirios», igualmente otros tres de autores casi desconocidos para nosotros: Yagües García, Nicolas Tello o Alberto Prosper.

En las actas que hemos consultado se da amplia noticia del número de socios que había en 1930 , exactamente ciento ochenta y cinco.

Finalmente las habituales cuentas: cinco mil pesestas de gastos y una cifra semejante de ingresos. 